\title{
ANALYSIS OF THE EXCITATION MECHANISM OF THE TRIGEMINAL MOTONEURON IN THE CAT
}

\author{
Mitsuru TAKATA, Ichiro Kato AND Yojiro KawAmuRA \\ Department of Oral-Physiology, Dental School, Osaka University, \\ Osaka, Japan
}

In our previous paper, we reported that the trigeminal motoneuron responded to pressure applied on the mandibular muscle in the cat $^{13}$. This trigeminal motoneuron response was strongly assumed to be due to deformation of a muscle spindle in the mandibular muscle.

Therefore, in this experiment we tried to determine the effect of succinylcholine on this trigeminal motoneuron activity, since succinylcholine has been reported as a stimulant to the muscle spindle ${ }^{2,3)}$.

\section{METHODS}

Ten adult cats were used. The method of recording responses of the trigeminal motoneuron were almost identical with those reported in the previous paper ${ }^{11}$.

Microelectrodes filled with $3 \mathrm{M} \mathrm{KCl}$ were used, but in some cases electrodes filled with $2 \mathrm{M} \mathrm{K}$-citrate were also used to record the potentials of trigeminal motoneurons.

A constant magnitude of pressure (about $30 \mathrm{~g} / \mathrm{mm}^{2}$ ) was vertically applied to the restricted site (focus spot) of the exposed surface of the masseter muscle by means of a small steel rod (about $1 \mathrm{~mm}^{2}$ at the round tip) driven by air pressure. Succinylcholine ( $\mathrm{Sch}$ ) dissolved in $0.9 \% \mathrm{NaCl}$ solution was administrated intravenously at various doses $(0.4 \mathrm{mg} / \mathrm{kg}-1.2 \mathrm{mg} / \mathrm{kg})$.

\section{RESULTS}

A motoneuron in the trigeminal motor nucleus was identified by the response induced by electrical stimulation of a low threshold afferent nerve fiber from the masseter muscle (FIG. 1). As shown in an intracellular recording (FIG. 2), subthreshold stimulation of the masseter nerve $(1 \mathrm{~V}, 0.5 \mathrm{msec})$ induced a deporalization of a motoneuron membrane about $5 \mathrm{mV}$ as shown in $S_{1}$ in FIG. 2. This depolarizing potential with a slow time decay is the excitatory post-synaptic potential (EPSP) already analysed in the sacral motoneuron by J. C. ECCLES and other investigators ${ }^{4}$. At the threshold stimulation with 1.5$2.0 \mathrm{~V}$, on ESPS is seen generating an action potential as indicated in $\mathrm{S}_{2}$ of

Received for publication March 29, 1967

高田 充, 加藤一郎, 河村洋二郎 
FIG. 2. The latency of the firing of the trigeminal motoneuron was about $1.2 \mathrm{msec}$.

In the next step, the effect of intravenously administered Sch on the activity of the trigeminal motoneuron, which was excited by light pressure applied on the masseter muscle, was analysed. $\mathrm{NaCl}$ solution $(0.9 \%)$ was used as the control solution and this solution did not show any effects on the motoneuron response to pressure applied on the masseter muscle (FIG. 3). In FIG. 3, C is before an $\mathrm{NaCl}$ intravenous injection, 1 is $1 \mathrm{~min}$. after the injection, and 2 is after $3 \mathrm{~min}$. Pressure was applied on the muscle during the upward deflection of a mechanogram (lower trace) in the record. The magnitude of the applied pressure was exactly the same in all these records.

The spike frequency of spontaneous discharges of the motoneuron was slightly increased by a $0.4 \mathrm{mg} / \mathrm{kg}$ Sch injection, but the response of the motoneuron to pressure on the muscle was not affected by this dose of Sch. However, both the spontaneous firing and pressure response of the trigeminal motoneuron were strongly affected by an injection of $0.8 \mathrm{mg} / \mathrm{kg} \mathrm{Sch}$.

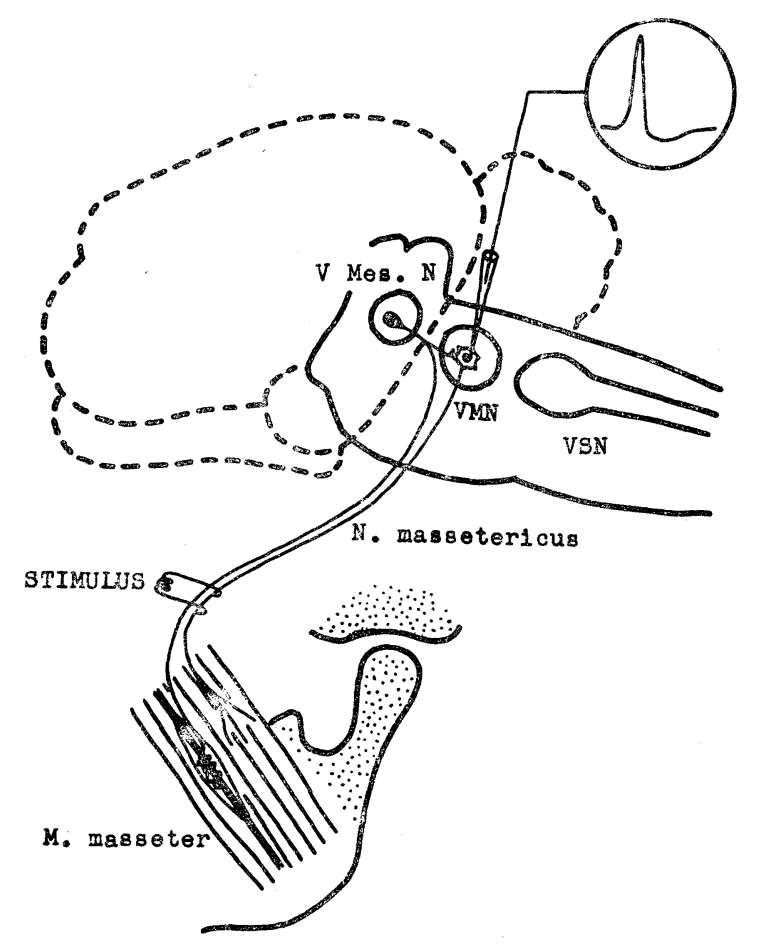

FIG. 1. Schematic diagram of recording procedure.

$\mathrm{V}$ Mes. N: Trigeminal mesencephalic nucleus.

V M : Trigeminal motor nucleus.

V S N : Trigeminal sensory nucleus. 
As shown in FIG. 4, spontaneous discharges of the motoneuron disappeared about $20 \mathrm{sec}$. after the $0.8 \mathrm{mg} / \mathrm{kg}$ Sch injection (FIG. 4(2)) but, about $40 \mathrm{sec}$. after the Sch injection the spontaneous discharges reappeared gradually and were facilitated with the lapse of time. This facilitatory effect of Sch became maximal at about 70 to $100 \mathrm{sec}$. after injection (FIG. 4(6)) and continued for about $4 \mathrm{~min}$. The spike frequency returned to the control level at about $5 \mathrm{~min}$. after the $0.8 \mathrm{mg} / \mathrm{kg}$ Sch injection (FIG. $4(7)$ ).

In the next step of the experiment, the pressure response of the motoneuron was recorded at the maximum stage of the Sch effect. Spontaneous firing of 11 spikes/sec. was increased to 21 spikes/sec. after the Sch injection, and the pressure response of the motoneuron was 25 spikes/sec. before and 52

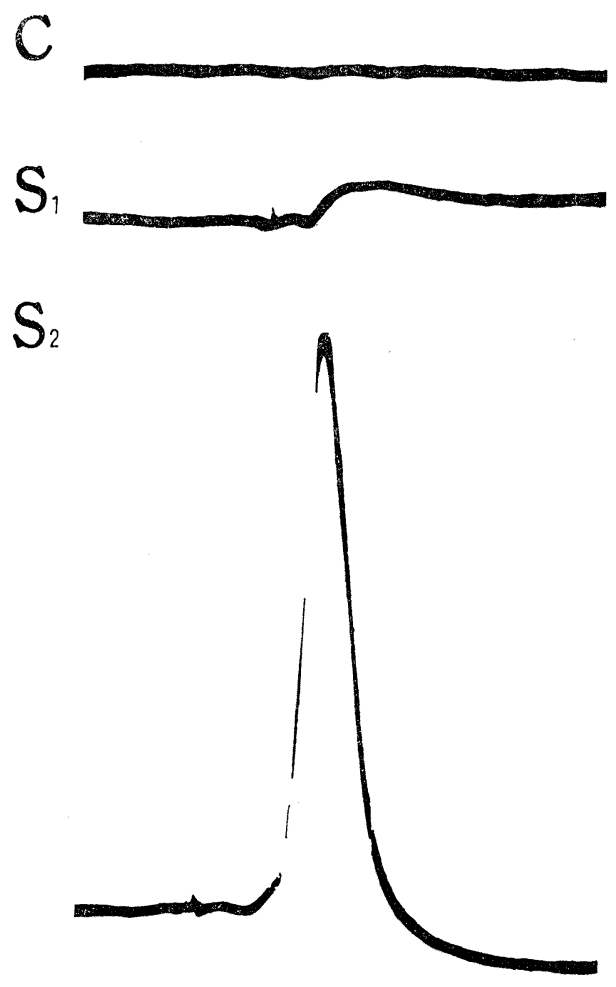

$\therefore \therefore \square \square$ I MSEC

FIG. 2. Intracellular potential of trigeminal motoneuron. induced by stimulation of low threshold masseter nerve. In the case of a subthreshold stimulus $(1 \mathrm{~V}, 0.5 \mathrm{msec})$ as. indicated in $S_{1}$, an afferent volley induced the excitatory post-synaptic potential. With a threshold stimulus $(1.5 \mathrm{~V}$, $0.5 \mathrm{msec}$.) as indicated in $\mathrm{S}_{2}$, an afferent volley initiated the all or nothing spike. 

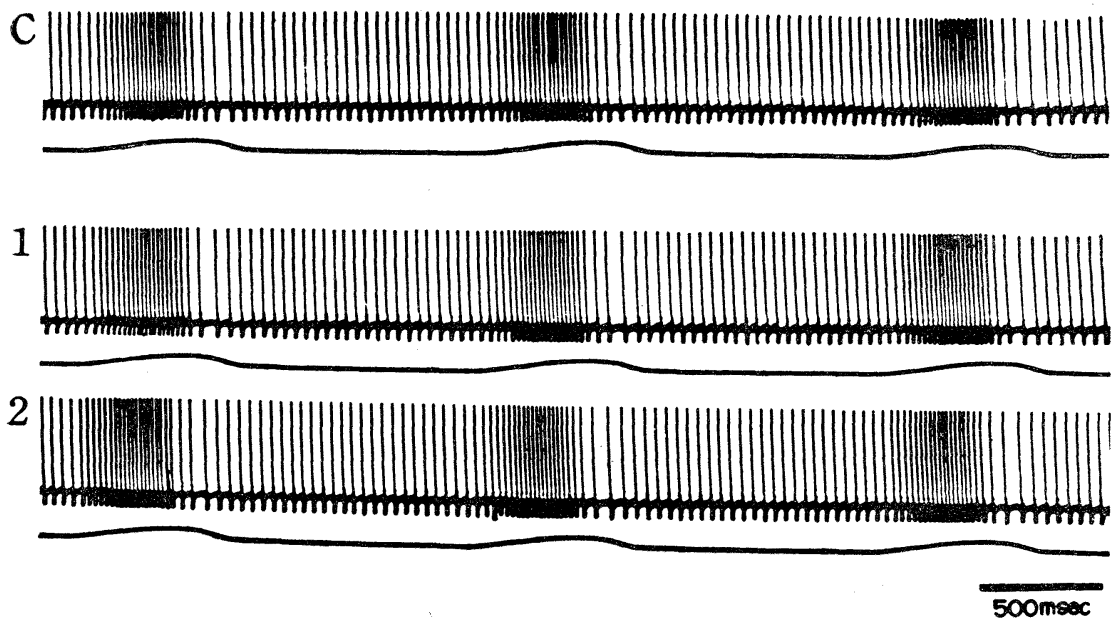

FIG. 3. NaCl solution ( $0.9 \%$ ) did not affect the motoneuron activity. C was the control, 1 was $1 \mathrm{~min}$. and 2 was $3 \mathrm{~min}$. after $0.9 \% \mathrm{NaCl}$ solution administration.

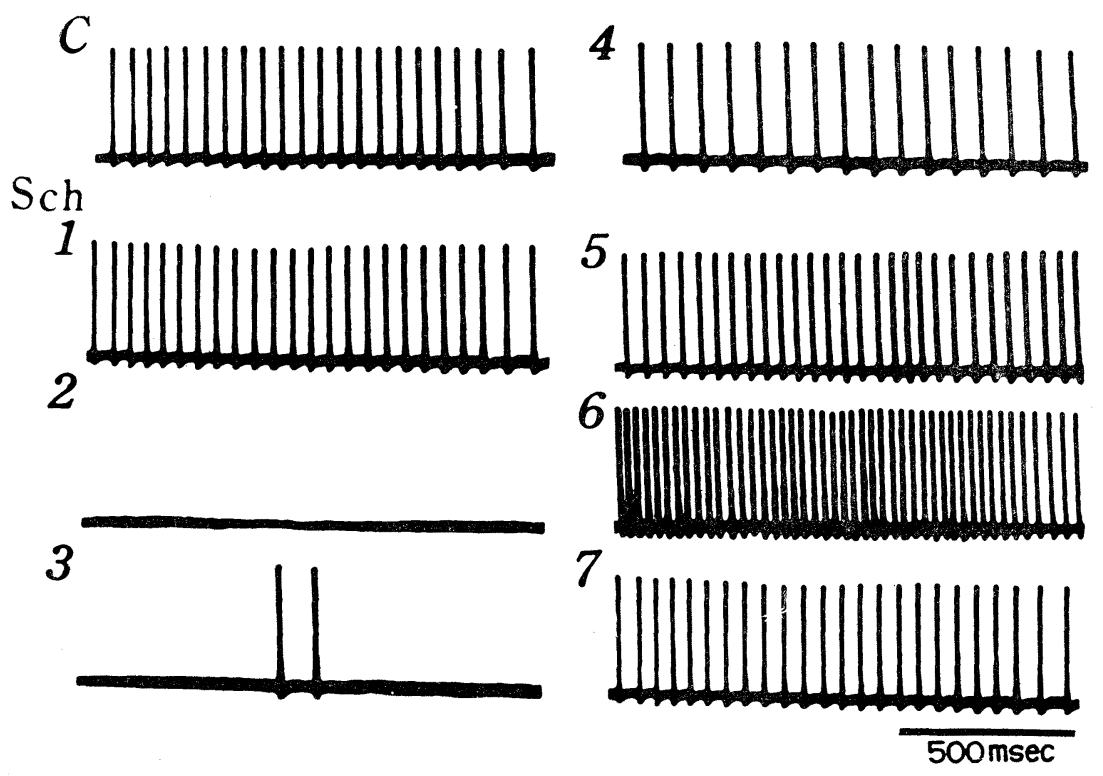

Fig. 4. The whole time course of excitation of the motoneuron under the intravenous administration of $0.8 \mathrm{mg} / \mathrm{kg} \mathrm{Sch}$. C was the control. 1 was $10 \mathrm{sec}$, 2 was $20 \mathrm{sec}, 3$ was $30 \mathrm{sec}$., 4 was $40 \mathrm{sec}$., 5 was $50 \mathrm{sec}$., 6 was $70 \mathrm{sec}$. and 7 was $5 \mathrm{~min}$. after intravenous administration. 

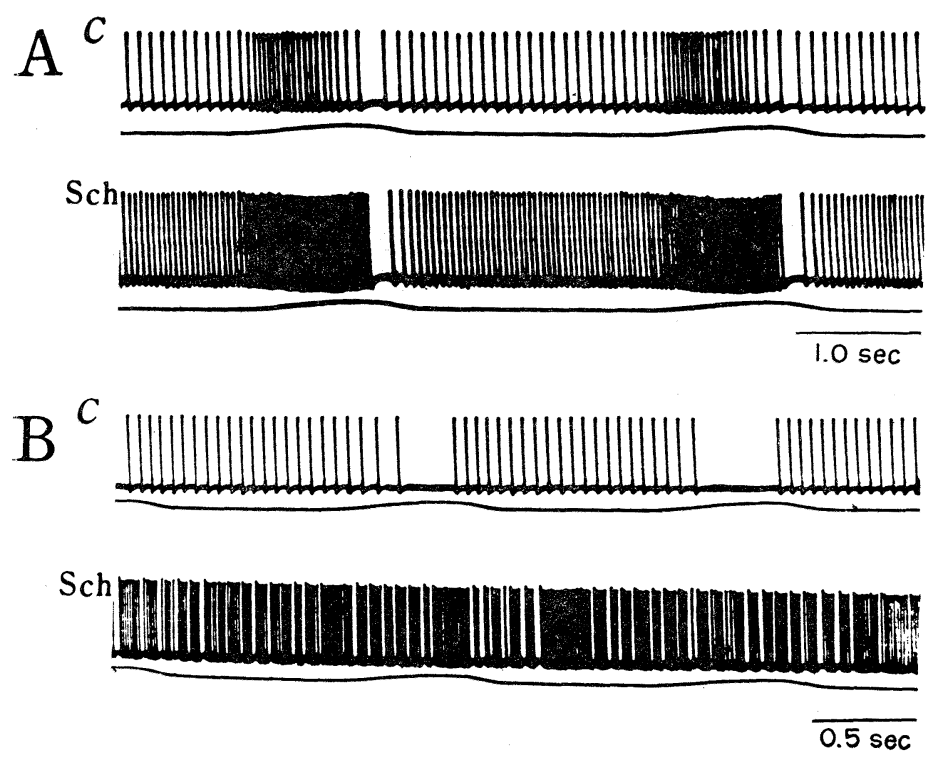

FIG. 5. The effect of various doses of Sch on the motoneuron activity. A was $1.0 \mathrm{mg} / \mathrm{kg} \mathrm{Sch}$ and B was $1.2 \mathrm{mg} / \mathrm{kg}$ Sch administration. C in each record was the control.
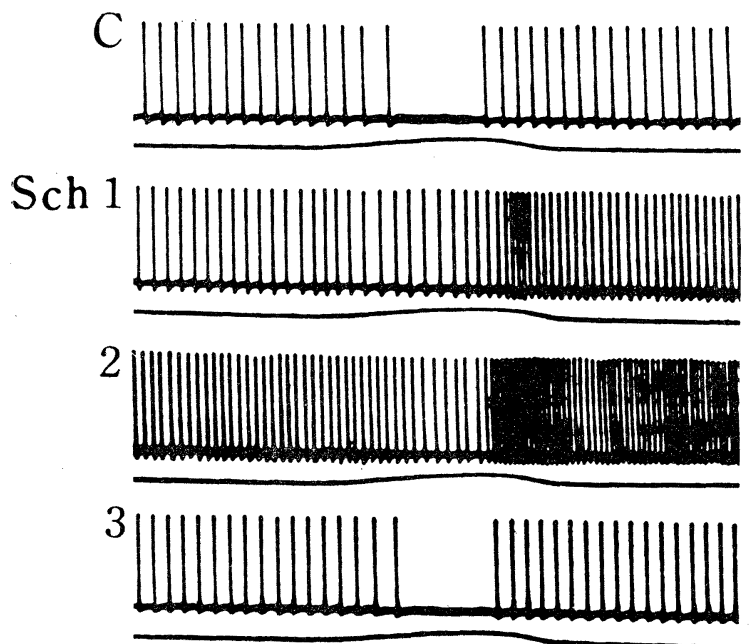

$500 \mathrm{meec}$

FIG. 6. The effect of $0.8 \mathrm{mg} / \mathrm{kg}$ Sch on the silent phase induced by pressure applied on the out-focus site in muscle was shown in this figure. $\mathrm{C}$ was the control. 1 was after $40 \mathrm{sec} ., 2$ was after $60 \mathrm{sec}$. and 3 was after $5 \mathrm{~min}$. 
spikes/sec. after the Sch injection. However, the ratio between the frequency of spontaneous firing and the pressure response was constant ( 1 to 2$)$ before and after Sch in jection (FIG. 5(A)).

In the case of $1.0 \mathrm{mg} / \mathrm{kg}$ of $\mathrm{Sch}$, the frequency of the spontaneous firing of the motoneuron increase to 4 times greater than that of the control. However, a higher concentration of Sch than $1.0 \mathrm{mg} / \mathrm{kg}$ induced some different effects on the motoneuron activity, and this high dose of Sch elicited a slight: muscle twitch. As shown in FIG. 5(B), the spontaneous firing of the motoneuron was changed into grouped discharges at $1 \mathrm{~min}$ after the $1.2 \mathrm{mg} / \mathrm{kg} \mathrm{Sch}$ injection.

On the contrary, as described in our previous paper ${ }^{1)}$, the firing of thesemotoneurons was stopped when pressure was applied about $20 \mathrm{~mm}$ away from. the focus spot in the same muscle. In this case, the muscle spindle might have been allowed to slacken by the pressure applied to the out-focus spot of the muscle and therefore it stopped sending afferent impulses.

In the next step of this experiment, to confirm the effects of Sch on an. intrafusal muscle fiber, responses of the trigeminal motoneuron to pressure: applied on the out-focus spot of the muscle were studied before and after Sch injection.

As shown in FIG. $6(\mathrm{C})$, a silent phase of the motoneuron activity was. induced by pressure application on the out-focus spot. However, this silent phase of the motoneuron activity was obscured at about $40 \mathrm{sec}$. after the application of $0.8 \mathrm{mg} / \mathrm{kg} \mathrm{Sch}$, and the motoneuron activity gradually recovered. to the control level after 5 min. (FIG. 6(3)).

\section{DISCUSSION}

BRINLING and SMITH ${ }^{3)}$ reported a stimulating action of Sch upon the muscle: spindle of the cat, and they mentioned that Sch decreased the resting discharge frequency of Ia afferent fibers within $30 \mathrm{sec}$. HUNT ${ }^{5)}$ also reported that Ach showed the same effect as Sch on the muscle spindle and it produced a contraction of the intrafusal muscle fiber.

In this experiment, the trigeminal motoneuron which was activated by light pressure applied on the restricted site of the masseter muscle showed remarkable activity after an intravenous administration of an optimal dose of Sch. Since the pattern of Sch effects on the trigeminal motoneuron described in this experiment are completely similar to those on the Ia fiber reported by BRINLING and $\mathrm{SMITH}^{3)}$, and also since Sch did not effect another adjacent neuron in the medulla, Sch possibly effects the muscle spindle and not the trigeminal motoneuron itself.

During the initial stage of Sch effect, spontaneous firing of the trigeminal motoneuron disappeared. This silent period might arise by contraction of the: 
extrafusal muscle fiber stimulated by Sch, and it means that the endplate of the extrafusal muscle fiber is more sensitive to Sch than the endplate of the intrafusal muscle fiber. During the maximum effect of Sch, the spontaneous firing of the trigeminal motoneuron remarkably increased. This phenomenon may be attributed to the contraction of intrafusal muscle fiber activated by Sch later than the extrafusal muscle fiber. EyzAGUIRRE ${ }^{6)}$ suggested that the intrafusal junction was more resistant to the action of curare than the extrafusal junction in amphibian muscle, but he did not recognize such phenomena in mammalian muscle. However, the present results suggest a difference in sensitivity to Sch between extrafusal and intrafusal muscle fibers even in mammalian muscle.

The response of the trigeminal motoneuron which was induced by light pressure application on a restricted small site in the masseter muscle was strongly affected by an optimal dose of Sch. This fact supports the concept that the trigeminal motoneuron response produced by pressure on the mandibular muscle, reported in our previous paper ${ }^{1)}$, is due to the deformation of the muscle spindle, and the firing of the trigeminal motoneuron by pressure to the muscle originates from the deformation of the muscle spindle.

\section{SUMMRAY}

Effects of Sch on responses of the trigeminal motoneuron induced by pressure applied to a restricted site on the masseter muscle were studied.

1. The optimal dose of Sch which effects the spontaneous discharges of the trigeminal motoneuron was about $0.8 \mathrm{mg} / \mathrm{kg}$. The spontaneous discharge of the trigeminal motoneuron disappeared within $20 \mathrm{sec}$. after the injection of $0.8 \mathrm{mg} / \mathrm{kg}$ Sch and this silent phase continued for about $20 \mathrm{sec}$. After this stage the spontaneous discharge reappeared gradually and reached the maximum firing level at about $100 \mathrm{sec}$. after Sch injection. At this stage the frequency of spontaneous firing was about 4 times greater than the control. This Sch effect continued for about 5 min. However, a super optimal dose of Sch $(1.2 \mathrm{mg} / \mathrm{kg})$ induced grouped discharges of the motoneuron and the muscle showed local twitching.

2. The endplate of the extrafusal muscle fiber was more sensitive to Sch than that of the intrafusal muscle fiber.

3. It was confirmed that the pressure response of the trigeminal motoneuron originates from the deformation of the muscle spindle.

This investigation was supported in part by USPHS research grant DE-01718 from the National Institute of Dental Research, National Institutes of Health, Bethesda, Maryland. 


\section{REFERENCES}

1) Kawamura, Y., Takata, M. And Kato, I. The role of spontaneous firing of the trigeminal motoneuron. Jap. J. Physiol., 18:7-14, 1968.

2) Granit, R., Skoglund, S. And Thesleff, S. Activation of muscle spindles by succinylcholine and decamethonium. The effect of curae. Acta Physiol. Scand., 28 : 134-151, 1953.

3) Brinling, J.C. And Smith, C. M. A characterization of the stimulation of mammalian muscle spindles by succinylcholine. J. Pharm. Exptl. Therap., 129: 56-60, 1959.

4) Eccles, J.C. The Physiology of Synapses. Springer-Verlag. Heidelberg, Germany, 1964.

5) Hunt, C.C. Drug effects on mammalian muscle spindles. Fed. Proc., 11: 75, 1952.

6) Eyzaguirre, C. Modulation of sensory discharges by efferent spindle excitation. J. Neurophysiol., 21 : 465-480, 1958. 